To cite this article: Talya Greene, Jasmine Harju-Seppänen, Mariam Adeniji, Charlotte Steel, Nick Grey, Chris R. Brewin, Michael A. Bloomfield \& Jo Billings (2021) Predictors and rates of PTSD, depression and anxiety in UK frontline health and social care workers during COVID-19, European
(c) 2021 The Author(s). Published by Informa UK Limited, trading as Taylor \& Francis Group.

冓 Published online: 10 Mar 2021.

Џll Article views: 851

View Crossmark data $\rtimes$

\section{Predictors and rates of PTSD, depression and anxiety in UK frontline health and social care workers during COVID-19}

\section{Talya Greene, Jasmine Harju-Seppänen, Mariam Adeniji, Charlotte Steel,} Nick Grey, Chris R. Brewin, Michael A. Bloomfield \& Jo Billings Journal of Psychotraumatology, 12:1, 1882781, DOI: 10.1080/20008198.2021.1882781

To link to this article: https://doi.org/10.1080/20008198.2021.1882781

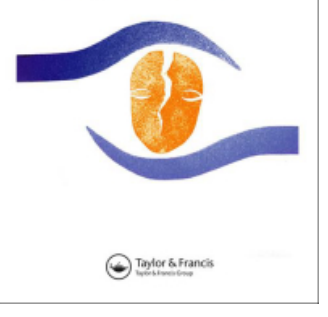

+ View supplementary material $₫$

Submit your article to this journal 


\title{
Predictors and rates of PTSD, depression and anxiety in UK frontline health and social care workers during COVID-19
}

\author{
Talya Greene (10), ${ }^{\mathrm{a}, \mathrm{b}}$, Jasmine Harju-Seppänen (1) ${ }^{\mathrm{b}, \mathrm{c}}$, Mariam Adeniji ${ }^{\mathrm{b}}$, Charlotte Steel ${ }^{\mathrm{b}}$, Nick Grey ${ }^{\mathrm{d}, \mathrm{e}}$, \\ Chris R. Brewin ${ }^{f}$, Michael A. Bloomfield ${ }^{b, g, h, i, j, k}$ and Jo Billings ${ }^{b}$
}

aDepartment of Community Mental Health, University of Haifa, Haifa, Israel; bivision of Psychiatry, University College London, London, UK; 'Division of Psychology and Language Sciences, University College London, London, UK; ${ }^{d}$ Sussex Partnership NHS Foundation Trust, Worthing, UK; eSchool of Psychology, University of Sussex, Brighton, UK; ${ }^{f}$ Clinical Educational \& Health Psychology, University College London, London, UK; ${ }^{9}$ Translational Psychiatry Research Group, Research Department of Mental Health Neuroscience, University College London, London, UK; ' $E$ pidemiology and Applied Clinical Research Department, University College London, London, UK; 'St Pancras Hospital, Camden and Islington NHS Foundation Trust, London, UK; jNational Institute for Health Research University College London Hospitals Biomedical Research Centre, University College Hospital, London, UK; ${ }^{k}$ National Hospital for Neurology and Neurosurgery, University College London Hospitals NHS Foundation Trust, London, UK

\begin{abstract}
Background: Studies have shown that working in frontline healthcare roles during epidemics and pandemics was associated with PTSD, depression, anxiety, and other mental health disorders.

Objectives: The objectives of this study were to identify demographic, work-related and other predictors for clinically significant PTSD, depression, and anxiety during the COVID-19 pandemic in UK frontline health and socia care workers (HSCWs), and to compare rates of distress across different groups of HCSWs working in different roles and settings.

Methods: A convenience sample $(n=1194)$ of frontline UK HCSWs completed an online survey during the first wave of the pandemic ( 27 May - 23 July 2020). Participants worked in UK hospitals, nursing or care homes and other community settings. PTSD was assessed using the International Trauma Questionnaire (ITQ); Depression was assessed using the Patient Health Questionnaire-9 (PHQ-9); Anxiety was assessed using the Generalized Anxiety Disorder Scale (GAD-7).

Results: Nearly $58 \%$ of respondents met the threshold for a clinically significant disorder (PTSD $=22 \%$; anxiety $=47 \%$; depression $=47 \%$ ), and symptom levels were high across occupational groups and settings. Logistic regression analyses found that participants who were concerned about infecting others, who could not talk with their managers if there were not coping, who reported feeling stigmatized and who had not had reliable access to personal protective equipment (PPE) were more likely to meet criteria for a clinically significant mental disorder. Being redeployed during the pandemic, and having had COVID were associated with higher odds for PTSD. Higher household income was associated with reduced odds for a mental disorder.

Conclusions: This study identified predictors of clinically significant distress during COVID-19 and highlights the need for reliable access to PPE and further investigation of barriers to communication between managers and staff.
\end{abstract}

\section{Predictores y tasas de TEPT, depresión y ansiedad en la primera línea de trabajadores sociales y de la salud en Reino Unido durante COVID-19}

Antecedentes: Los estudios han mostrado que el trabajo en roles de primera línea de salud durante epidemias y pandemias se asoció a TEPT, depresión, ansiedad y otros trastornos de salud mental.

Objetivos: Los objetivos de este estudio fueron identificar predictores demográficos, predictores relacionados al trabajo y otros, para TEPT, depresión y ansiedad clínicamente significativos durante la pandemia por COVID-19 en la primera línea de trabajadores sociales y de la salud (HSCWs), y comparar las tasas de afectación entre los diferentes grupos de HSCWs trabajando en diferentes roles y contextos.

Métodos: Una muestra por conveniencia $(n=1194)$ de la primera línea de HSCWs en Reino Unido completó un cuestionario en línea durante la primera ola de la pandemia ( 27 de mayo - 23 de julio de 2020). Los participantes trabajaban en hospitales del Reino Unido, centros asistenciales u otros contextos clínicos comunitarios. Se evaluó TEPT usando el Cuestionario Internacional de Trauma (ITQ); la depresión fue evaluada usando el Cuestionario sobre la salud del paciente 9 (PHQ-9); la ansiedad fue evaluada usando la Escala sobre Trastorno Ansioso (GAD-7).

Resultados: Cerca del 58\% de los participantes cumplieron el umbral para algún trastorno clínicamente significativo (TEPT $=22 \%$; ansiedad $=47 \%$; depresión $=47 \%$ ), y los niveles de síntomas fueron altos entre los grupos y contextos ocupacionales. Los análisis de regresión logística encontraron que los participantes que estaban preocupados respecto a contagiar a otros; quienes no pudieron hablar con sus administradores cuando no se estaban adaptando a la situación; quienes reportaron sentirse estigmatizados y quienes no tuvieron acceso a elementos de protección personal (EPP) confiables, tuvieron mayor probabilidad

\section{ARTICLE HISTORY}

Received 5 November 2020

Revised 5 January 2021

Accepted 16 January 2021

KEYWORDS

COVID-19; frontline workers;

health and social care;

pandemics; distress; PTSD;

depression; anxiety

\section{PALABRAS CLAVE}

COVID-19; trabajadores de primera línea; cuidado de salud y cuidado social;

pandemias; sufrimiento

TEPT; Depresión; Ansiedad

关键词

COVID-19; 一线工作者; 卫 生和社会护理; 疫情; 精神 痛苦; PTSD; 抑郁; 焦虑

\section{HIGHLIGHTS}

- During the first UK COVID19 wave, $22 \%$ met criteria for PTSD, 47\% met criteria for anxiety, and $47 \%$ met criteria for depression. - Being concerned about infecting others, not being able to tell managers about not coping, feeling stigmatized, and not having reliable access to personal protective equipment raised odds for distress.

CONTACT Talya Greene tgreene@univ.haifa.ac.il D Department of Community Mental Health, University of Haifa, 199 Aba Houshy Avenue, Haifa 3498838, Israel

(4) Supplemental data for this article can be accessed here. 
de cumplir los criterios para un trastorno mental clínicamente significativo. Ser redistribuido a otras funciones durante la pandemia, y haber tenido COVID se asociaron a mayores probabilidades de desarrollar TEPT. Un mayor ingreso familiar se asoció con menores probabilidades de desarrollar un trastorno mental.

Conclusiones: Este estudio identificó predictores para afectación clínicamente significativa durante la pandemia por COVID-19 y resalta la necesidad de un acceso confiable a EPP y de mayor investigación sobre las barreras de comunicación entre los administradores y los equipos de trabajo.

\section{COVID-19期间英国一线卫生和社会护理工作者的PTSD，抑郁和焦虑的预} 测因素和发生率

背景: 研究表明，在流行病和疫情中在一线卫生护理工作与PTSD，抑郁，焦虑和其他精神疾 病有关。

目的: 本研究旨在确定英国一线卫生和社会护理工作者 (HSCW) 在COVID-19疫情期间临床 上显著的PTSD，抑郁和焦虑的人口统计学，工作相关因素和其他预测因素，并比较在不同角 色和环境中工作的不同HCSW组之间的精神痛苦。

方法: 在第一波疫情期间 (2020年5月27日至7月23日), 英国一线HCSW的方便样本 $(n=$ 1194）完成了在线调查。参与者在英国的医院，疗养院或其他社区环境中工作。使用了国 际创伤问卷 (ITQ) 评估PTSD; 使用患者健康问卷9 (PHQ-9) 评估抑郁; 使用广泛性焦虑量表 (GAD-7) 评估焦虑。

结果: 将近58\%的受访者达到了临床上显著疾病的阈值 (PTSD $=22 \%$; 焦虑症 $=47 \%$; 抑郁 症 $=47 \%$ ), 并且各职业组和环境的症状水平都很高。Logistic回归分析发现，担心感染他人 者，如果没有应对措施就无法与管理者交谈者，报告被污名化者且无法个人防护设备 (PPE) 可靠来源者更可能符合具有临床意义的精神障碍标准。在疫情期间被调遣，患过COVID与 PTSD发生几率高有关。家庭收入增加与精神障碍的几率降低有关。

结论: 本研究确定了COVID-19期间临床上显著精神痛苦的预测因素，并强调了对于有PPE可 靠来源以及进一步考查管理人员与员工之间沟通障碍的需求。

\section{Introduction}

Since the COVID-19 global pandemic began, frontline health and social care workers (HSCWs) have been repeatedly identified as being at high risk for severe psychological distress (Billings et al., 2020; Gersons, Smid, Smit, Kazlauskas, \& McFarlane, 2020; Greenberg, Docherty, Gnanapragasam, \& Wessely, 2020; Javakhishvili et al., 2020; Shanafelt, Ripp, \& Trockel, 2020), and emerging research seems to support this (Billings, Ching, Gkofa, Greene, \& Bloomfield, 2020; Braquehais et al., 2020; Lai et al., 2020; Pappa et al., 2020). The COVID-19 situation is dynamic within, and variable across, countries with a range of health care systems. It is important to examine mental distress among HSCWs in different countries at different phases of the pandemic to guide national responses as well as learn from the international context. Evidence is required not only to evaluate how widespread mental distress is among frontline HSCWs but, crucially, to identify risk factors. This will help identify which frontline HSCWs are at highest risk, inform evidence-based primary prevention strategies during anticipated subsequent peaks associated with COVID-19 and guide secondary prevention treatment strategies to minimize distress, as well as increase understanding of occupational stressors for HSCWs in general.

During a pandemic, frontline HSCWs are at increased risk of infection while also dealing with working conditions that are more difficult and demanding than usual (Shanafelt et al., 2020).
Studies have shown that working in healthcare roles during epidemics and pandemics such as SARS, MERS, and Ebola disease, was associated with PTSD, depression, anxiety, and other mental health disorders (Allan et al., 2020; Brooks, Dunn, Amlôt, Rubin, \& Greenberg, 2018; de Pablo et al., 2020; Preti et al., 2020). Research has also highlighted potential risk factors, including being tasked to directly work with patients suspected of having the virus (Kisely et al., 2020; Maunder et al., 2003; McAlonan et al., 2007; Styra et al., 2008), working as a nurse (Billings et al., 2020; de Pablo et al., 2020; Preti et al., 2020), being a parent of dependent children (Kisely et al., 2020) and being a woman (Serrano-Ripoll et al., 2020). HCSWs may have concerns both about being infected, and about passing the disease onto others (Bai et al., 2004; Billings et al., 2020), and may feel stigmatized as a result of their role (Bai et al., 2004; Brooks et al., 2018; de Pablo et al., 2020).

Emerging evidence from research on the COVID19 pandemic indicates high rates of mental disorders among HSCWs in many countries, including China, USA, India, and Italy (Braquehais et al., 2020; Carmassi et al., 2020; Chew et al., 2020; Krishnamoorthy, Nagarajan, Saya, \& Menon, 2020; Pappa et al., 2020; Shechter et al., 2020). Studies have identified potential risk factors (Braquehais et al., 2020; Lai et al., 2020), especially concerns about personal safety given the elevated rates of morbidity and mortality among healthcare workers which may have been exacerbated where there was inadequate access to appropriate personal protective equipment 
(PPE) (Braquehais et al., 2020; Urooj, Ansari, Siraj, Khan, \& Tariq, 2020; Wang, Zhou, \& Liu, 2020), and among staff directly working with patients with confirmed or suspected COVID-19 (Kang et al., 2020). Additionally, being a woman (Lai et al., 2020) and working as a nurse (Luceño-Moreno, TalaveraVelasco, García-Albuerne, \& Martín-García, 2020) were both associated with higher mental distress. Staff may feel they have provided suboptimal treatment due to insufficient staff and resources, and working with social restrictions, which may cause distress sometimes referred to as moral injury (Williamson, Murphy, \& Greenberg, 2020). In some locations and settings (e.g. Northern Italy) there was a need to ration treatments which has been especially challenging for healthcare workers, compounding an already difficult situation (Cavallo, Donoho, \& Forman, 2020).

In England, it has been estimated that one in ten COVID-19 cases around the peak of the first wave occurred in frontline HSCWs (Torjesen, 2020). A survey of UK HSCWs published in April 2020 found that half of those surveyed reported that their mental health had deteriorated during the pandemic (Thomas, Quilter-Pinner, \& Research, 2020). In a survey of UK doctors in May 2020, 45\% reported experiencing depression, anxiety, stress, burnout or other mental health problems during the pandemic (BMA, 2020), and a large survey of UK nurses published in August 2020 found that $76 \%$ reported an increase in their stress since the outbreak of COVID19 , and over half were concerned about their mental health (Royal College of Nursing, 2020). It is clear that working in health and social care during COVID-19 in the UK has been challenging. To date, however, studies have not been published assessing rates of PTSD, depression, and anxiety among different UK HSCW groups during COVID-19, nor have any studies been published examining risk factors for these mental health disorders during the pandemic in the UK.

The existing studies, both those examining COVID-19 related distress, and those from previous pandemics, have focused predominantly on medical staff (nurses and doctors). Some have also included allied health professionals but have rarely included clinical support staff or auxiliary frontline healthcare workers such as receptionists, porters and cleaners. Importantly, the psychological impact of pandemics on social care workers has been largely neglected, yet care homes have been particularly badly affected by COVID-19 (Gordon et al., 2020). Studies based on wider samples are urgently needed.

The Frontline-COVID study is an online survey for which baseline data were collected during the first wave of the COVID-19 pandemic. The study aimed to identify demographic, work-related and other predictors for psychological distress (clinically significant levels of PTSD, depression, and/or anxiety) during the pandemic in UK frontline HSCWs, and to compare rates of PTSD, depression and anxiety across different groups of HCSWs working in a wide variety of roles, including clinical, non-medical, allied healthcare and auxiliary roles.

\section{Methods}

\subsection{Participants and procedure}

Frontline health and social care workers across the UK were invited to participate in the study via a social media campaign (Facebook adverts, Twitter and Facebook posts, and emails to wellbeing leads at a number of UK hospitals, with a request to circulate to staff). The questionnaire was administered using online survey methods, via the Qualtrics data collection platform. Data were collected between 27 May 2020-23 July 2020. This represents the post-peak phase of the initial COVID-19 wave in the UK; during this period, deaths related to COVID in the UK rose from 37,430 to 41,160 , while reported weekly deaths fell from 2000 (29 May 2020) to 231 (24 July 2020) (Public Health England, 2020). Participants gave informed consent online before proceeding to the questionnaire. Ethical approval for the FrontlineCOVID study was granted by the UCL Ethics Committee (Ethics ID: 18341/001).

In total, 2447 individuals opened the link to read the participant information sheet, 1311 consented to participate, and 1205 provided data. Participants who indicated that they did not work in healthcare $(n=5)$ were excluded. In cases where participants completed the questionnaire on more than one occasion, the first response was used and the second was excluded from analysis $(n=6)$. This resulted in a sample of 1194 individuals.

\subsection{Measures}

The study survey included background questions regarding participants' gender, age, income, ethnicity, whether they were in a relationship, whether they were caring for children at home, and UK region of work. Participants were asked to indicate their job role which was then operationalized into the following categories: Nurse or midwife; carer (mostly working in care home or community settings); clinical support staff (including healthcare assistants); doctor; non-clinical staff working in health and social care settings (including cleaners, porters, administrators, maintenance, security roles); allied healthcare professionals (including physiotherapists, occupational therapists, paramedics, and other allied roles as defined by the NHS); and any other roles. 
Participants also reported their work setting, which was operationalized as follows: Hospital, nursing or care home, and any other community setting. A series of questions assessed: access to PPE (yes vs no or sometimes); whether they were redeployed into a new team or to a new role as part of the emergency response to the COVID-19 pandemic (currently or previously redeployed vs no); whether they had been infected with COVID-19 (confirmed or suspected vs no); using alcohol, cigarettes or other substances more than usual to cope (yes vs no); and whether they could tell their manager or team leader if they were not coping (yes vs no). Single Likert scales ranging from 0 ('not at all') to 4 ('extremely') assessed: whether participants worried they would be rejected or stigmatized for being an NHS worker; whether they were worried about being infected with COVID-19; and whether they were worried about infecting others with COVID-19.

PTSD symptoms were assessed using the International Trauma Questionnaire (ITQ; Cloitre et al., 2018). This is a self-report questionnaire, based on the ICD-11 criteria for PTSD and Complex PTSD, which has demonstrated reliability and validity. As all those meeting criteria for Complex PTSD also need to meet criteria for PTSD, we only examined the PTSD threshold in order to identify those with clinical levels of distress. For the identification of participants meeting PTSD thresholds, individuals report how often they have experienced six core symptoms of PTSD (two from each of three subscales) in the last month and three functional impairment items related to these subscales, on a 5-point Likert scale ranging from 0 ('not at all') to 4 ('extremely'). The diagnostic threshold for PTSD is met if at least one of two symptoms from each PTSD symptom subscale are endorsed (scored as $\geq 2$ ) and there is endorsement of at least one of the functional impairment items. In total, 1110 individuals completed the first nine items of the ITQ. Cronbach's alpha in the current study was 0.88 .

Depression symptoms were assessed using the Patient Health Questionnaire-9 (Kroenke, Spitzer, \& Williams, 2001) (PHQ-9). This is a widely used 9item self-report questionnaire corresponding to the DSM-5 criteria for depression. Previous studies indicate that the PHQ-9 has high internal consistency and test-retest reliability (Kroenke et al., 2001). In the current study, participants reported how often symptoms occurred during the previous fortnight on a four-point Likert scale ranging from 0 ('not at all') to 3 ('very much'). Total scores are the sum of all item scores (0-27); a score of 10 or higher typically indicates moderate depression. Altogether, 1017 individuals completed the PHQ-9. Cronbach's alpha in the current study was 0.90 .
Anxiety symptoms were assessed using the Generalized Anxiety Disorder Scale-7 (Spitzer, Kroenke, Williams, \& Löwe, 2006) (GAD-7). This is a 7-item self-report questionnaire developed to indicate severity of anxiety symptoms and has demonstrated high internal consistency and test-retest reliability. Participants report how much they have been bothered by each symptom over the past two weeks on a 4-point Likert Scale ranging from 1 ('not at all') to 3 ('more than half the days'). Total scores are the sum of all item scores (0-21). In UK clinical settings, a score of 8 is used for clinically significant anxiety. Altogether, 994 individuals completed the GAD-7. Cronbach's alpha for the current study was 0.93 .

\subsection{Data analysis}

Four separate logistic regressions were performed. The regressions examined the predictors for depression, anxiety and PTSD separately, and also investigated the predictors of meeting the thresholds for at least one of the three conditions. Participants were excluded if they had missing data on any of the predictor variables. Additionally, participants were excluded if they had not completed the relevant outcome measure. This resulted in the following sample sizes: 851 for the analysis investigating if participants met the threshold for at least one of the three disorders, 943 for PTSD, 876 for depression, and 854 for anxiety. Analyses were conducted in R (version 3.6.2) using the $g l m$ package. The p-value threshold was set as 0.05 .

\section{Results}

The mean age of the participants was 41.5 years (range $=18.5-86.5 ; \mathrm{SD}=11.8$ ). Overall, the majority of the sample were female (92.4\%), white (90.8\%) and married or living with a partner $(63 \%)$. Of the participants, $75.6 \%$ reported that they had worked directly to treat, support or care for patients with COVID, $17.7 \%$ reported having had confirmed COVID, and a further $12.9 \%$ reported having had suspected COVID. For more participant details, see Table 1. For details of numbers of individuals in each role by setting, please see supplementary material.

Of the study participants, 391 (32.8\%) reported that they were using alcohol, cigarettes, and other substances more than usual, and 360 (30.2\%) reported that they could not tell their manager or team leader if they were not coping. There were 668 participants (56\%) who reported being moderately to extremely worried about catching COVID, 927 (77.6\%) were moderately to extremely worried about infecting others, and 435 (36.5\%) reported feeling moderately to extremely stigmatized. 
Table 1. Characteristics of the study participants.

\begin{tabular}{|c|c|}
\hline \multicolumn{2}{|c|}{ Sample characteristics $(N=1194)$} \\
\hline Demographic & $N(\%)$ \\
\hline \multicolumn{2}{|l|}{ Age } \\
\hline $18-29$ & $254(21.27 \%)$ \\
\hline $30-44$ & $371(31.08 \%)$ \\
\hline $45-59$ & $407(34.08 \%)$ \\
\hline $60+$ & $41(3.43 \%)$ \\
\hline Missing & $76(6.37 \%)$ \\
\hline \multicolumn{2}{|l|}{ Gender } \\
\hline Woman & $1103(92.38 \%)$ \\
\hline Man & $84(7.04 \%)$ \\
\hline Other & $6(0.51 \%)$ \\
\hline Missing & $1(0.08 \%)$ \\
\hline \multicolumn{2}{|l|}{ Ethnicity } \\
\hline Asian/Asian British & $39(3.27 \%)$ \\
\hline Black/Black British & $18(1.51 \%)$ \\
\hline Mixed race (White and Black/Black British) & $6(0.50 \%)$ \\
\hline Mixed race (other) & $19(1.59 \%)$ \\
\hline White (British, Irish, other) & $1084(90.79 \%)$ \\
\hline Chinese/Chinese British & $3(0.25 \%)$ \\
\hline Middle Eastern/Middle Eastern British & $5(0.42 \%)$ \\
\hline Other ethnic group & $18(1.51 \%)$ \\
\hline Prefer not to say/Missing & $2(0.17 \%)$ \\
\hline \multicolumn{2}{|l|}{ Annual Household Income (£) } \\
\hline Less than 16,000 & $86(7.20 \%)$ \\
\hline 16,000 to 29,999 & $327(27.39 \%)$ \\
\hline 30,000 to 59,999 & 467 (39.11\%) \\
\hline More than 60,000 & $232(19.43 \%)$ \\
\hline Missing/prefer not to answer & $82(6.87 \%)$ \\
\hline \multicolumn{2}{|l|}{ Relationship } \\
\hline In a relationship & 867 (72.61\%) \\
\hline Single & $324(27.20 \%)$ \\
\hline Missing & $3(0.25 \%)$ \\
\hline \multicolumn{2}{|l|}{ Caring for children at home } \\
\hline Yes & $453(37.94 \%)$ \\
\hline No & $736(61.64 \%)$ \\
\hline Missing & $5(0.42 \%)$ \\
\hline \multicolumn{2}{|l|}{ UK region of work } \\
\hline East Midlands & $81(6.78 \%)$ \\
\hline East of England & $77(6.45 \%)$ \\
\hline London & $138(11.56 \%)$ \\
\hline North East & $78(6.53 \%)$ \\
\hline North West & 167 (13.99\%) \\
\hline Northern Ireland & $14(1.17 \%)$ \\
\hline Scotland & $83(6.95 \%)$ \\
\hline South East & $160(13.40 \%)$ \\
\hline South West & $116(9.72 \%)$ \\
\hline Wales & $64(5.36 \%)$ \\
\hline West Midlands & $108(9.05 \%)$ \\
\hline Yorkshire and the Humber & $106(8.88 \%)$ \\
\hline Missing & $2(0.17 \%)$ \\
\hline \multirow{2}{*}{\multicolumn{2}{|c|}{$\begin{array}{l}\text { Work-related } \\
\text { Job Role }\end{array}$}} \\
\hline & \\
\hline Allied healthcare & $136(11.39 \%)$ \\
\hline Carer & $105(8.79 \%)$ \\
\hline Clinical support role & $204(17.09 \%)$ \\
\hline Doctor & $46(3.85 \%)$ \\
\hline Non-clinical staff & $62(5.19 \%)$ \\
\hline Nurse or midwife & $504(42.21 \%)$ \\
\hline Other roles & $133(11.14 \%)$ \\
\hline Missing & $4(0.34 \%)$ \\
\hline \multicolumn{2}{|l|}{ Work Setting } \\
\hline Any hospital & $638(53.43 \%)$ \\
\hline Nursing or care home & $177(29.65 \%)$ \\
\hline Other community setting & $354(29.65 \%)$ \\
\hline Other & $25(14.82 \%)$ \\
\hline Missing & 0 \\
\hline $\begin{array}{l}\text { COVID-related } \\
\text { Access to PPE }\end{array}$ & \\
\hline Yes & $753(63.07 \%)$ \\
\hline Sometimes & 351 (29.40\%) \\
\hline No & $48(4.02 \%)$ \\
\hline Missing & $42(3.52 \%)$ \\
\hline Redeployed during pandemic & \\
\hline Yes & $888(74.37 \%)$ \\
\hline No & $288(24.12 \%)$ \\
\hline Missing & $18(1.51 \%)$ \\
\hline
\end{tabular}

Table 1. (Continued).

\begin{tabular}{lc}
\hline \multicolumn{2}{c}{ Sample characteristics $(N=1194)$} \\
\hline Demographic & $N(\%)$ \\
\hline Direct work with COVID patients & \\
Yes & $903(75.63 \%)$ \\
No & $273(22.86 \%)$ \\
Missing & $18(1.51 \%)$ \\
Had COVID (Confirmed and suspected) & \\
Yes & $365(30.57 \%)$ \\
No & $809(67.76 \%)$ \\
Missing & $20(1.68 \%)$ \\
\hline
\end{tabular}

\subsection{Rates of clinically significant distress}

Rates of clinically significant distress for PTSD, depression and anxiety were assessed (see Table 2). Notably, $57.9 \%$ of participants met criteria for clinically significant levels of distress.

\subsubsection{Predictors}

Due to the group sizes on some of the predictor variables, some categories were merged: doctors and non-clinical staff were merged with the 'other' category for the roles variable; ethnic background was dichotomized such that participants identifying as Black, Asian or other ethnic minorities were merged into one category, and participants identifying as White were placed in the second category.

Figure 1 shows the level of PTSD, depression and anxiety symptoms, by professional role or occupational group (see supplementary Figure 1 for an expanded version of this figure specifying levels of symptoms for doctors and non-clinical staff). ANOVAs showed that the only significant group differences were between allied healthcare professionals and clinical support staff, with clinical support staff reporting more symptoms across all three disorders. We also compared PTSD, depression and anxiety symptoms by setting, and found that the only significant difference was that participants working in nursing or care home settings had higher levels of PTSD symptoms compared with other community settings. For full analyses and for zero-order associations of other study variables please see the supplementary material.

We investigated the predictors of meeting thresholds for at least one of PTSD, depression and anxi-

Table 2. Rates for clinically significant distress.

\begin{tabular}{lc}
\hline PTSD $N=1110$ for mean score, $N=1095$ for diagnosis & \\
\hline Mean (SD) & $7.96(5.81)$ \\
PTSD present (N/\%) & $246(22.47 \%)$ \\
Depression $\boldsymbol{N}=\mathbf{1 0 1 7}$ & \\
Mean (SD) & $9.97(6.57)$ \\
Depression present (N/\%) & $477(46.90 \%)$ \\
Anxiety $\boldsymbol{N}=\mathbf{9 9 4}$ & \\
Mean (SD) & $8.49(6.14)$ \\
Anxiety present (N/\%) & $470(47.28 \%)$ \\
PTSD, Depression and/or Anxiety $\boldsymbol{N}=\mathbf{9 8 8}$ & \\
Anxiety, Depression and/or PTSD (N/\%) & $572(57.89 \%)$ \\
\hline
\end{tabular}


PTSD symptoms by role
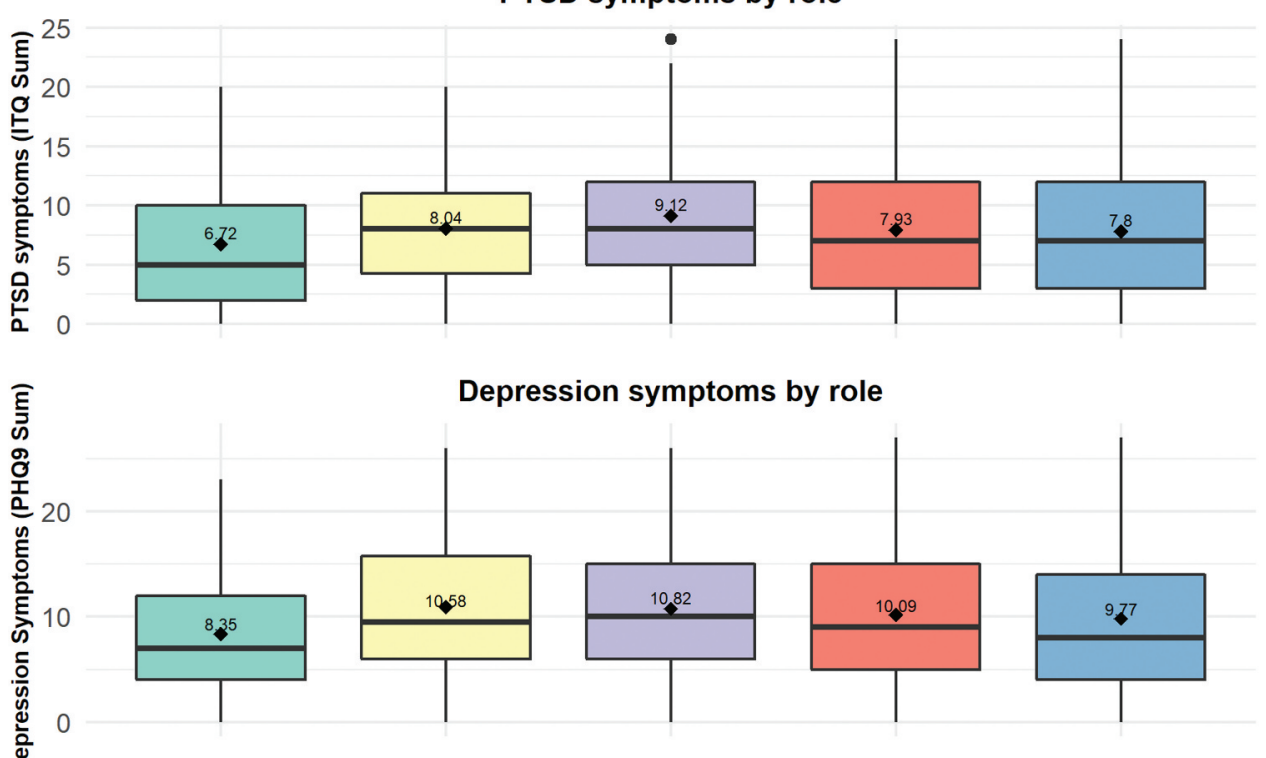

Anxiety symptoms by role

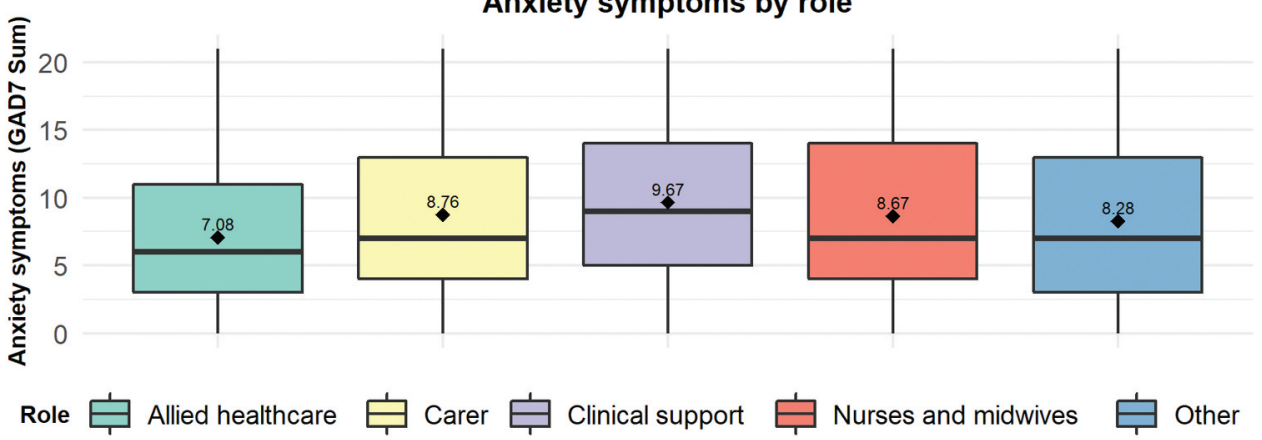

Figure 1. Clinically significant symptoms by role.

The mean value is denoted by the diamond point on the box plot.

ety, and also for meeting diagnostic thresholds for each disorder separately, using logistic regressions (Table 3).

Three variables significantly predicted distress across all four models: being able to tell their manager if they are not coping; being worried about infecting others; and perceived stigma. Participants who reported not having had reliable access to PPE had higher odds of meeting criteria for both depression and anxiety, as well as any clinically significant disorder. Having been redeployed during COVID19 was associated with higher odds for PTSD. Nurses and midwifes were significantly more likely to meet criteria for PTSD compared with carers and clinical support staff, and they were also more likely to meet criteria for any clinically significant disorder vs allied healthcare professionals, carers, and the heterogeneous 'other roles' group. Participants who were worried about being infected had higher odds of meeting criteria for PTSD. Having had COVID (confirmed or suspected) was also associated with increased odds of meeting criteria for any clinically significant disorder. The group with the highest income were least likely to meet criteria for PTSD and anxiety, and also had lower odds for any clinically significant disorder.

\section{Discussion}

This study examined rates and predictors of clinically significant PTSD, depression and anxiety in frontline health and social care workers across the UK during the first wave of the COVID-19 pandemic. Our findings indicate that clinically significant distress was common, with over $57 \%$ of respondents meeting the threshold for PTSD, anxiety and/or depression. Nearly a third of respondents reported using alcohol, cigarettes or other substances more than usual to cope. Participants who were concerned about infecting others, who could not tell their managers if they were not coping, who reported feeling stigmatized due to their role, who had not had reliable access to PPE, and who had caught COVID were more likely to have a clinically significant mental disorder. Being redeployed during the pandemic and being worried about catching COVID were associated with a higher likelihood of meeting criteria for PTSD. Higher 
Table 3. Logistic regressions for clinically significant PTSD, depression and anxiety.

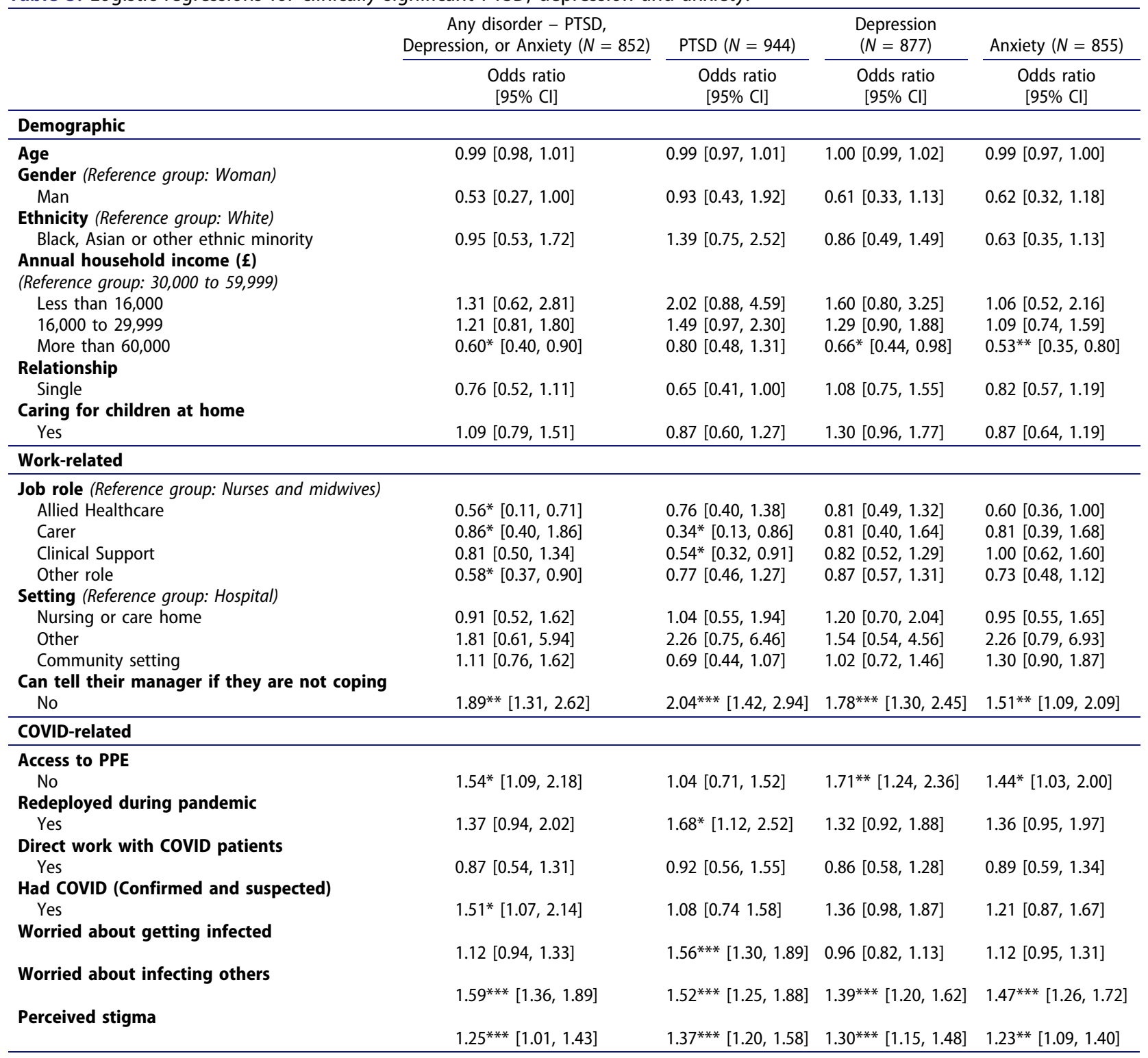

Note: ${ }^{*} p<0.05,{ }^{* *} p<0.005,{ }^{* * *} p<0.0005$. Estimations could not be calculated for the 'Other' category in Gender due to small group size.

household income was associated with reduced odds for a mental disorder.

In line with previous findings, respondents were more concerned about infecting others, than with being infected themselves (Shechter et al., 2020). Importantly, being concerned about passing COVID19 on was a robust predictor of clinically significant disorders. Participants who had not had reliable access to PPE (approximately a third of participants) also had higher rates of clinically significant distress. These results emphasize the importance of providing adequate PPE to HSCWs throughout an infectious disease outbreak not only to protect their physical health but in order reduce the likelihood of mental distress. If HSCWs perceive themselves to be unsafe and vulnerable to contracting an infectious disease they may actively avoid loved ones in order to protect them (Billings et al., 2020). Furthermore, it may be that others avoid socializing with or being in close proximity to HSCWs due to fear of infection, which may be experienced as rejection and stigmatization. As a result, HSCWs are likely to have reduced social support from family and friends - a key protective factor for mental health - at a time when they have heightened levels of stress and distress.

Crucially, over $30 \%$ of participants reported that they could not tell their manager how they were coping, and this was associated with the highest odds of distress across most models. In addition, being redeployed was a risk factor for both PTSD and anxiety. Recently, interventions aimed at improving healthcare team leaders' awareness of mental distress among their staff, and most importantly their skills in engaging in supportive conversations have been implemented in some settings (Greenberg \& Tracy, 2020). The findings from the current study 
support the need for these kinds of interventions, and they may be especially helpful for staff who are redeployed to new roles or teams and lack their usual support network. It is important to acknowledge, however, that there may be complicated reasons behind workers not feeling able to talk to managers about their coping which warrant exploration. Furthermore, HSCWs are likely to be best helped by a network of support, including managers, peers and professional mental health support (Billings et al., 2020).

In the current study, we directly compared nurses and midwives, allied healthcare professionals, carers, clinical support staff. We found that nurses and midwifes were more likely to meet criteria for PTSD compared with carers and clinical support staff, and to meet criteria for at least one mental disorder compared with allied healthcare professionals and carers. Although previous studies also found nurses to be particularly distressed (Billings et al., 2020; de Pablo et al., 2020; Preti et al., 2020), most examined differences between nurses and doctors, with little or no comparison with other HSCW groups. Notably, an examination of the levels of PTSD, anxiety and depression symptoms among the different groups in this study did not indicate that nurses and midwives were at highest risk; all had similarly high symptoms of PTSD, depression and anxiety symptoms compared with nurses. Furthermore, for the current study, most of the occupational groups (including pharmacists, doctors, cleaners, porters and administrators among others) were too small to be entered as separate comparison groups and were collapsed into one heterogeneous 'other roles' group. Thus, it is likely that among this 'other group' there were particular occupational groups that were also highly distressed, and possibly even more so than those groups in the current study. We recommend conducting further studies examining COVID-19 distress in HSCWs, especially with non-clinical staff working in health and social care settings, who have been typically neglected in research to date.

In contrast to some other studies, gender was not a significant predictor of distress and neither was identifying as Black, Asian or other ethnic minority. These findings should be treated with caution as the majority of participants identified as women (92\%) and white (91\%), and it may be that there was insufficient power to detect differences. We recommend that further studies oversample Black, Asian and other ethnic minority groups, especially as emerging evidence indicates they have been disproportionately affected by the COVID-19 pandemic in the UK (Rimmer, 2020). Additionally, unlike some studies, we did not find that working directly with patients who were suspected or confirmed to be infected was a significant predictor of distress. This may reflect the fact that during the period of data collection COVID19 was relatively widespread, and so even HSCWs who were not directly working with COVID patients perceived that they were at risk.

There are some limitations to this study. Although the sample was reasonably large, it was a convenience sample recruited through social media, and therefore is vulnerable to self-selection bias. Thus, it is not a representative sample, and prevalence estimates for the whole HSCW population in the UK should not be derived from this study. Second, the questionnaires were self-report, rather than standardized clinicianadministered diagnostic interviews. Third, we were not able to include other occupational groups in the comparisons due to the small numbers of participants in each group. Finally, although this is part of a longitudinal study for which data are currently being collected, the current paper reports only on the first wave of this study, therefore it is not possible to draw conclusions as to the direction of these relationships.

\subsection{Clinical implications}

This study found evidence of high levels of distress among the participants. While these rates may be over-estimates, they are indicative of clinically significant need. For many, this acute distress will naturally resolve and should not be pathologised (Billings et al., 2020; Lamb, Greenberg, Stevelink, \& Wessely, 2020). Furthermore, there is a temptation to rush to put in place formal interventions, yet for many HSCWs this will not be necessary. Nevertheless, for some frontline HSCWs, their distress and other symptoms will be severe and have the potential to become chronic. These cases need to be detected early and treated promptly in order to protect the individual HSCWs and the overall functioning of the entire health and social care system during the pandemic. The findings that distress levels were relatively high across the different occupational groups and work settings emphasizes the need to ensure services reach out to all these groups.

\section{Conclusions}

This study highlights the importance of reliable access to PPE, not only for the physical safety of staff, but also to reduce their feelings that they are at risk of catching COVID, and crucially, the perception that they are a risk to others. It is important to examine the role that managers can play in reducing staff distress, especially for redeployed staff. Differentiating between those with temporary distress, and those who are on a trajectory for longerterm mental health problems, is a priority. Identifying risk factors for PTSD, depression and 
anxiety among HSCWs, and providing treatment for those who need it is critical given that subsequent waves of COVID-19 and other healthcare crises are inevitable.

\section{Data availability statements}

The data that support the findings of this study are available from the corresponding author, TG, upon reasonable request. The data are not publicly available due to privacy reasons.

\section{Disclosure statement}

No potential conflict of interest was reported by the authors.

\section{Funding}

No external funding was received for this study

\section{ORCID}

Talya Greene (D) http://orcid.org/0000-0002-3044-2841 Jasmine Harju-Seppänen (D) http://orcid.org/0000-00029027-2119

\section{References}

Allan, S. M., Bealey, R., Birch, J., Cushing, T., Parke, S., Sergi, G., ... Meiser-Stedman, R. (2020). The prevalence of common and stress-related mental health disorders in healthcare workers based in pandemic-affected hospitals: A rapid systematic review and meta-analysis. European Journal of Psychotraumatology, 11 (1), 1810903. doi:10.1080/20008198.2020.1810903

Bai, Y., Lin, -C.-C., Lin, C.-Y., Chen, J.-Y., Chue, C.-M., \& Chou, P. (2004). Survey of stress reactions among health care workers involved with the SARS outbreak. Psychiatric Services, 55(9), 1055-1057.

Billings, J., Ching, B. C. F., Gkofa, V., Greene, T., \& Bloomfield, M. (2020). Healthcare workers experiences of working on the frontline and views about support during COVID-19 and comparable pandemics: A rapid review and meta-synthesis. medRxiv, 70.

Billings, J., Greene, T., Kember, T., Grey, N., El-Leithy, S., Lee, D., ... Brewin, C. R. (2020). Supporting hospital staff during COVID-19: Early interventions. Occupational Medicine, 327-329.

BMA. (2020). 14 May 2020 BMA COVID-19 tracker survey wave 4. Retrieved from https://www.bma.org.uk/media/ 3205/bma-covid-19-tracker-survey-14-may-2020.pdf

Braquehais, M. D., Vargas-Cáceres, S., Gómez-Durán, E., Nieva, G., Valero, S., Casas, M., \& Bruguera, E. (2020). The impact of the COVID-19 pandemic on the mental health of healthcare professionals. QJM: $A n$ International Journal of Medicine, 113(9), 613-617.

Brooks, S. K., Dunn, R., Amlôt, R., Rubin, G. J., \& Greenberg, N. (2018). A systematic, thematic review of social and occupational factors associated with psychological outcomes in healthcare employees during an infectious disease outbreak. Journal of Occupational and Environmental Medicine, 60(3), 248-257.
Carmassi, C., Foghi, C., Dell'Oste, V., Cordone, A., Bertelloni, C. A., Bui, E., \& Dell'Osso, L. (2020). PTSD symptoms in healthcare workers facing the three coronavirus outbreaks: What can we expect after the COVID-19 pandemic. Psychiatry Research, 292, 113312.

Cavallo, J. J., Donoho, D. A., \& Forman, H. P. (2020, March). Hospital capacity and operations in the coronavirus disease 2019 (covid-19) pandemic-planning for the nth patient. In JAMA health forum (Vol. 1, No. 3, p. e200345). American Medical Association.

Chew, N. W., Lee, G. K., Tan, B. Y., Jing, M., Goh, Y., Ngiam, N. J., .. Shanmugam, G. N. (2020). A multinational, multicentre study on the psychological outcomes and associated physical symptoms amongst healthcare workers during COVID-19 outbreak. Brain, Behavior, and Immunity, 88, 559-565.

Cloitre, M., Shevlin, M., Brewin, C. R., Bisson, J. I., Roberts, N. P., Maercker, A., .. Hyland, P. (2018). The International Trauma Questionnaire: Development of a self-report measure of ICD-11 PTSD and complex PTSD. Acta Psychiatrica Scandinavica, 138(6), 536-546.

de Pablo, G. S., Serrano, J. V., Catalan, A., Arango, C., Moreno, C., Ferre, F., ... Solmi, M. (2020). Impact of coronavirus syndromes on physical and mental health of health care workers: Systematic review and meta-analysis. Journal of Affective Disorders, 275, 48-57.

Gersons, B. P. R., Smid, G. E., Smit, A. S., Kazlauskas, E., \& McFarlane, A. (2020). Can a 'second disaster' during and after the COVID-19 pandemic be mitigated? European Journal of Psychotraumatology, 11(1), 1815283. doi:10.1080/ 20008198.2020.1815283

Gordon, A. L., Goodman, C., Achterberg, W., Barker, R. O., Burns, E., Hanratty, B., ... Schols, J. (2020). Commentary: COVID in care homes-challenges and dilemmas in healthcare delivery. Age and Ageing, 49(5), 701-705.

Greenberg, N., Docherty, M., Gnanapragasam, S., \& Wessely, S. (2020). Managing mental health challenges faced by healthcare workers during covid-19 pandemic. BMJ, 368. doi:10.1136/bmj.m1211

Greenberg, N., \& Tracy, D. (2020). What healthcare leaders need to do to protect the psychological well-being of frontline staff in the COVID-19 pandemic. BMJ Specialist Journals. doi:10.1136/leader-2020-000273

Javakhishvili, J. D., Ardino, V., Bragesjö, M., Kazlauskas, E., Olff, M., \& Schäfer, I. (2020). Trauma-informed responses in addressing public mental health consequences of the COVID-19 pandemic: Position paper of the European Society for Traumatic Stress Studies (ESTSS). European Journal of Psychotraumatology, 11(1), 1780782. doi:10.1080/ 20008198.2020.1780782

Kang, L., Li, Y., Hu, S., Chen, M., Yang, C., Yang, B. X., ... Ma, X. (2020). The mental health of medical workers in Wuhan, China dealing with the 2019 novel coronavirus. The Lancet Psychiatry, 7(3), e14.

Kisely, S., Warren, N., McMahon, L., Dalais, C., Henry, I., \& Siskind, D. (2020). Occurrence, prevention, and management of the psychological effects of emerging virus outbreaks on healthcare workers: Rapid review and metaanalysis. BMJ, 369. doi:10.1136/bmj.m1642

Krishnamoorthy, Y., Nagarajan, R., Saya, G. K., \& Menon, V. (2020). Prevalence of psychological morbidities among general population, healthcare workers and COVID-19 patients amidst the COVID-19 pandemic: A systematic review and meta-analysis. Psychiatry Research, 293, 113382.

Kroenke, K., Spitzer, R. L., \& Williams, J. B. (2001). The PHQ-9: Validity of a brief depression severity measure. Journal of General Internal Medicine, 16(9), 606-613. 
Lai, J., Ma, S., Wang, Y., Cai, Z., Hu, J., Wei, N., ... Li, R. (2020). Factors associated with mental health outcomes among health care workers exposed to coronavirus disease 2019. JAMA Network Open, 3(3), e203976e203976.

Lamb, D., Greenberg, N., Stevelink, S. A., \& Wessely, S. (2020). Mixed signals about the mental health of the NHS workforce. The Lancet Psychiatry, 7(12), 1009-1011.

Luceño-Moreno, L., Talavera-Velasco, B., García-Albuerne, Y., \& Martín-García, J. (2020). Symptoms of posttraumatic stress, anxiety, depression, levels of resilience and burnout in spanish health personnel during the COVID19 Pandemic. International Journal of Environmental Research and Public Health, 17(15), 5514.

Maunder, R., Hunter, J., Vincent, L., Bennett, J., Peladeau, N., Leszcz, M., ... Mazzulli, T. (2003). The immediate psychological and occupational impact of the 2003 SARS outbreak in a teaching hospital. CMAJ: Canadian Medical Association Journal, 168(10), 1245-1251.

McAlonan, G. M., Lee, A. M., Cheung, V., Cheung, C., Tsang, K. W., Sham, P. C., ... Wong, J. G. (2007). Immediate and sustained psychological impact of an emerging infectious disease outbreak on health care workers. The Canadian Journal of Psychiatry, 52(4), 241-247.

Pappa, S., Ntella, V., Giannakas, T., Giannakoulis, V. G., Papoutsi, E., \& Katsaounou, P. (2020). Prevalence of depression, anxiety, and insomnia among healthcare workers during the COVID-19 pandemic: A systematic review and meta-analysis. Brain, Behavior, and Immunity, 88, 901-907.

Preti, E., Di Mattei, V., Perego, G., Ferrari, F., Mazzetti, M., Taranto, P., ... Calati, R. (2020). The psychological impact of epidemic and pandemic outbreaks on healthcare workers: Rapid review of the evidence. Current Psychiatry Reports, 22(8), 1-22.

Public Health England. (2020). Coronavirus (COVID-19) in the UK: Deaths. Retrieved from https://coronavirus.data.gov.uk/ deaths

Rimmer, A. (2020). Covid-19: Two thirds of healthcare workers who have died were from ethnic minorities. BMJ, 369. https://doi-org.ezproxy.haifa.ac.il/10.1136/bmj.m1621

Royal College of Nursing. (2020). Building a better future for nursing: RCN members have their say. London, UK. Retrieved from https://www.rcn.org.uk/professionaldevelopment/publications/rcn-builiding-a-better-futurecovid-pub-009366
Serrano-Ripoll, M. J., Meneses-Echavez, J. F., Ricci-Cabello, I., Fraile-Navarro, D., Fiol-deRoque, M. A., Moreno, G. P., ... Gonçalves-Bradley, D. (2020). Impact of viral epidemic outbreaks on mental health of healthcare workers: A rapid systematic review and meta-analysis. Journal of Affective Disorders, 277, 347-357.

Shanafelt, T., Ripp, J., \& Trockel, M. (2020). Understanding and addressing sources of anxiety among health care professionals during the COVID-19 pandemic. JAMA, 323(21), 2133-2134.

Shechter, A., Diaz, F., Moise, N., Anstey, D. E., Ye, S., Agarwal, S., ... Chang, B. (2020). Psychological distress, coping behaviors, and preferences for support among New York healthcare workers during the COVID-19 pandemic. General Hospital Psychiatry, 66, 1-8.

Spitzer, R. L., Kroenke, K., Williams, J. B., \& Löwe, B. (2006). A brief measure for assessing generalized anxiety disorder: The GAD-7. Archives of Internal Medicine, 166(10), 1092-1097.

Styra, R., Hawryluck, L., Robinson, S., Kasapinovic, S., Fones, C., \& Gold, W. L. (2008). Impact on health care workers employed in high-risk areas during the Toronto SARS outbreak. Journal of Psychosomatic Research, 64 (2), 177-183.

Thomas, C., Quilter-Pinner, H., \& Research, I. F. P. P. (2020). Care fit for carers: Ensuring the safety and welfare of NHS and social care workers during and after Covid-19. Institute for Public Policy Research. Retrieved from www.ippr.org/files/ 2020-04/care-fit-for-carers-april20.pdf

Torjesen, I. (2020). Covid-19: One in 10 cases in England occurred in frontline health and social care staff. BMJ: British Medical Journal (Online), 370. doi:10.1136/bmj. $\mathrm{m} 2717$

Urooj, U., Ansari, A., Siraj, A., Khan, S., \& Tariq, H. (2020). Expectations, Fears and Perceptions of doctors during Covid-19 Pandemic. Pakistan Journal of Medical Sciences, 36(COVID19-S4). doi:10.12669/ pjms.36.COVID19-S4.2643

Wang, J., Zhou, M., \& Liu, F. (2020). Reasons for healthcare workers becoming infected with novel coronavirus disease 2019 (COVID-19) in China. Journal of Hospital Infection, 105(1), 100-101.

Williamson, V., Murphy, D., \& Greenberg, N. (2020). COVID-19 and experiences of moral injury in front-line key workers. Occupational Medicine, 70(5), 317-319. 